\title{
EFFect Of Rice Husk on the SANd Mold Properties AND THE QUALITY OF CAST IRON
}

\author{
Charnnarong Saikaew, Chaiyan Poolpraserd \\ Department of Industrial Engineering, Khon Kaen University, Khon Kaen 40002, Thailand
}

\begin{abstract}
In the iron casting industry, the recycled sand degrades quality of sand mold that causes product defects. The mixture components of sand mold should be considered in order to improve the quality of casting products. This work aimed to investigate the effect of rice husk as a composition in sand mold on the mechanical properties of the sand mold and the iron casting samples using general factorial design of experiments and statistical analysis technique. The results showed that the content and particle size of rice husk powder significantly affected the compressive strength and permeability of sand mold. However, the hardness was not enhanced by adding rice husk powder with different percentages and particle sizes. Rough surface of the sample made with the molding sand mixture of rice husk powder was better than that made with the conventional mixture of the sand mold.
\end{abstract}

Keywords: Iron sand casting; rice husk; statistical analysis; quality improvement; hardness;
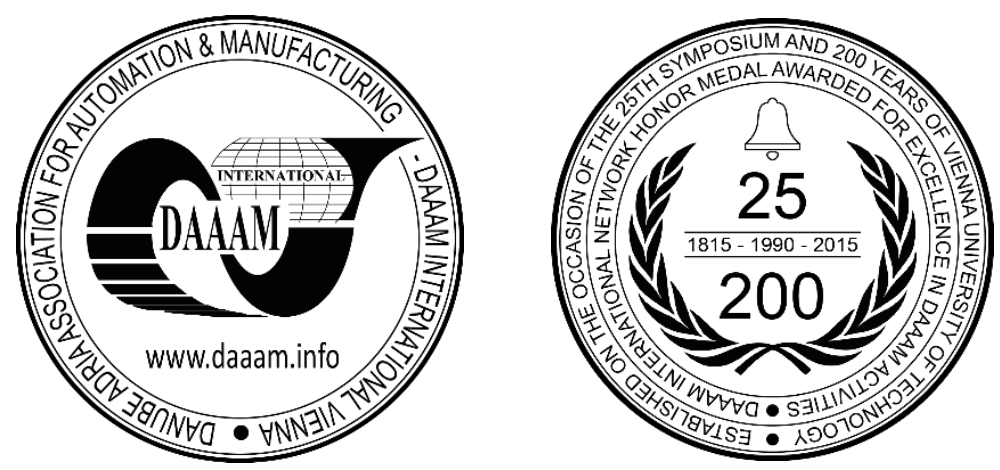

This Publication has to be referred as: Saikaew, C[harnnarong] \& Poolpraserd, C[haiyan] (2016). Effect of Rice Husk on the Sand Mold Properties and the Quality of Cast Iron, Proceedings of the 26th DAAAM International Symposium, pp.1038-1044, B. Katalinic (Ed.), Published by DAAAM International, ISBN 978-3-902734-07-5, ISSN 1726-9679, Vienna, Austria DOI: 10.2507/26th.daaam.proceedings. 146 


\section{Introduction}

The demands of economic competition have motivated many researches in the field of sand mold composition improvement affecting the quality of iron sand casting products. The quality of iron sand casting products can be assured when the sand mold compositions are controlled [1]. An iron sand casting manufacturer in Khon Kaen, Thailand would like to investigate the effect of adding rice husk powder with different contents and particle sizes on the sand mold mechanical properties and the surface quality of iron sand casting products. Rice husk is an agro-industrial waste which contains amorphous silica leading to its possibility to be transformed into a supplement for sand mold mixtures. Many researchers have investigated the effects of rice husk on the quality characteristics and the mechanical properties of the concrete. The particle size of rice husk as an additive for high performance concrete affected the pozzolanic activity as silica fume [2]. Concrete containing rice husk ash improved higher compressive strength [3]. They stated that blending of Portland cement with rice husk ash leaded to lower porosity and finer pore structures. Apart from rice husk adding in cement, glass epoxy hybrid composites were filled with rice husk particulates in different weight proportions to improve the mechanical properties and erosion wear performance of the hybrid composite [4]. They found that the hardness, tensile modulus, and impact energy of the hybrid composites were improved. The hardness increased from $34 \mathrm{HV}$ to $43 \mathrm{HV}$ with the increase in rice husk content from $0 \mathrm{wt} \%$ to $15 \mathrm{wt} \%$. Erosion wear resistance of the composite increased by adding 3 wt.\% of rice husk.

In foundry, modified corn starch was used as a main binder for sand core to improve bonding property in application to iron sand casting due to its suitable viscosity, good hygroscopicity resistance, higher specific bonding strength, compressive strength, and tensile strength compared to furane resin bonded sand [5]. Potato starch was used as an alternative binder of a new sand core in foundry. A liquid water-soluble modified starch was developed and conducted to produce sand cores of various castings with products quality improvement, production efficiency and manufacturing costs [6]. However, researchers has not used rice husk as a binder composition in sand mold to improve its mechanical properties and the quality of metal sand casting products.

In this work, one of design of experiments approaches, general factorial design and statistical analysis technique were used to investigate the effect of rice husk in sand mold on the mechanical properties and surface quality of the iron casting samples. Automatic Rockwell Galileo hardness tester was employed to compare hardness values of iron casting samples made with various sand molds of different quantities and particle sizes of rice husk powder and that of the conventional mixture of the sand mold from the factory. Moreover, stereo microscope and SEM were utilized to observe the surface quality and the dispersion of microstructure of iron casting samples.

\section{Materials and research methodology}

Molding sand mixture consisted of four components: recycle molding sand, bentonite, water, and rice husk. The recycled sand and bentonite for the experiments were supplied from Asia Foundry Co., Ltd. located in Khon Kaen, Thailand. Bentonite and typical micrograph were shown in Fig. 1 (a) and (c), respectively. Rice husk was obtained from Mueang district, Khon Kaen, Thailand. Rice husk was sieved through three levels of 106, 212, and $425 \mu \mathrm{m}$. Rice husk typical micrograph were shown in Fig. 1 (b) and (d), respectively. Typical SEM micrographs revealed that particle shapes of bentonite and rice husk were micro porous and irregular. The proportionate quantities of the molding sand mixture were poured and mixed according to the general factorial design matrix in a Muller at a university laboratory. The mixed sand was transferred into a precision specimen tube to make A.F.S. standard test specimens. The mixed sand was compacted by dropping a $62.36 \mathrm{~N}$ sliding weight at a fixed distance. The specimens of the sand mold were ready to be tested for their properties (i.e., compressive strength and permeability). The compressive strength test was carried out using a universal sand strength testing machine whereas the permeability test was done using a calibrated permeability meter. Detailed experiments of the compressive strength and permeability tests were found in [7].

Research procedure was described as follows: 1) prepare rice husk powder by grinding in a vibrating mill for 45 min in order to reduce particle size of the rice husk, 2) prepare A.F.S. standard test specimens by varying the content of rice husk powder from $1 \mathrm{wt} . \%, 2 \mathrm{wt} . \%, 3 \mathrm{wt} . \%$ and $4 \mathrm{wt} . \%$ and particle size of 106, 212, and $425 \mu \mathrm{m}$ with the recycled sand, bentonite, and water of 90-99.9 wt.\%, 0.05-5wt.\%, and 0.05-5wt.\% based on iron sand casting manufacturer's experience and [8,9], 3) carry out compressive strength and permeability experiments with A.F.S. standard test specimens with three samples for each run based on general factorial design matrix, 4) perform analysis of variance to investigate the effect of content and particle size of the rice husk on the compressive strength and permeability, 5) pour melting iron into the sand mold (see Fig. 2 (a), 6) compare surface and mechanical property (i.e., hardness) of the iron casting samples (see Fig. 2 (b) by Olympus SZX 9 zoom stereo microscope imaging and an automatic Rockwell Galileo hardness tester model ERGOTEST DIGI 25 RS, respectively. 


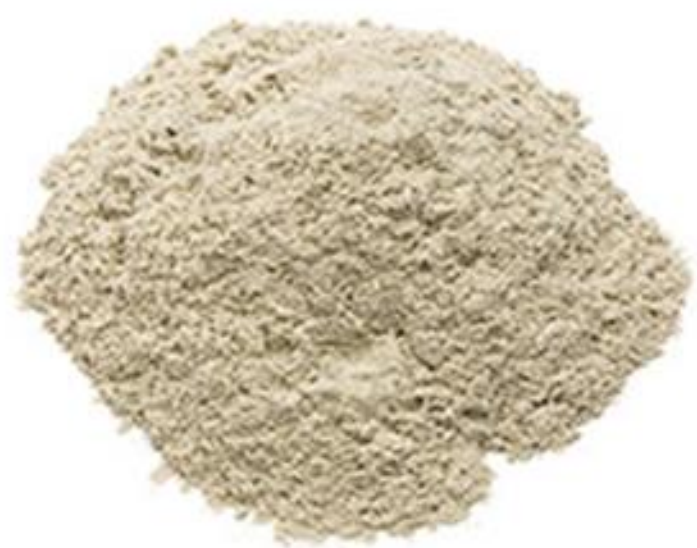

(a)

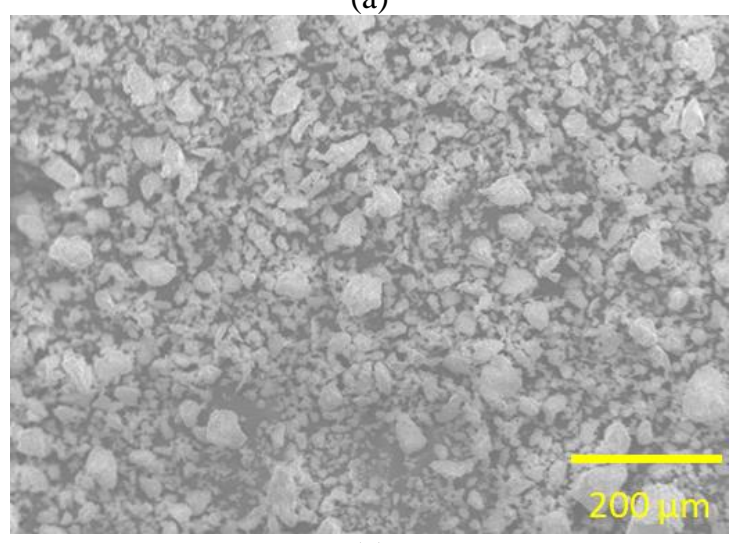

(c)

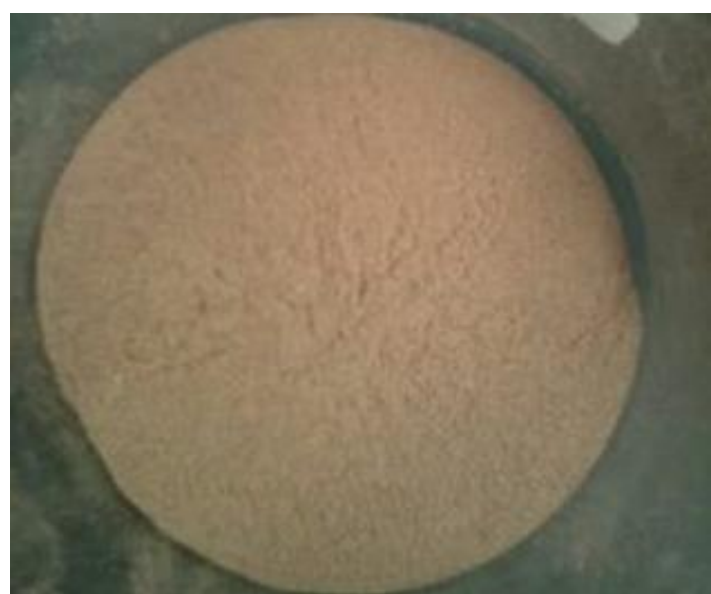

(b)

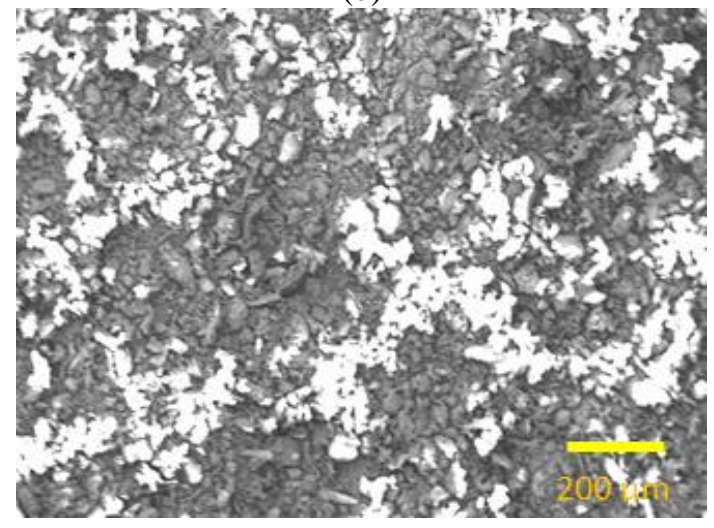

(d)

Fig. 1. (a) Bentonite; (b) rice husk powder; (c) typical micrographs of bentonite ; (d) rice husk podwder.

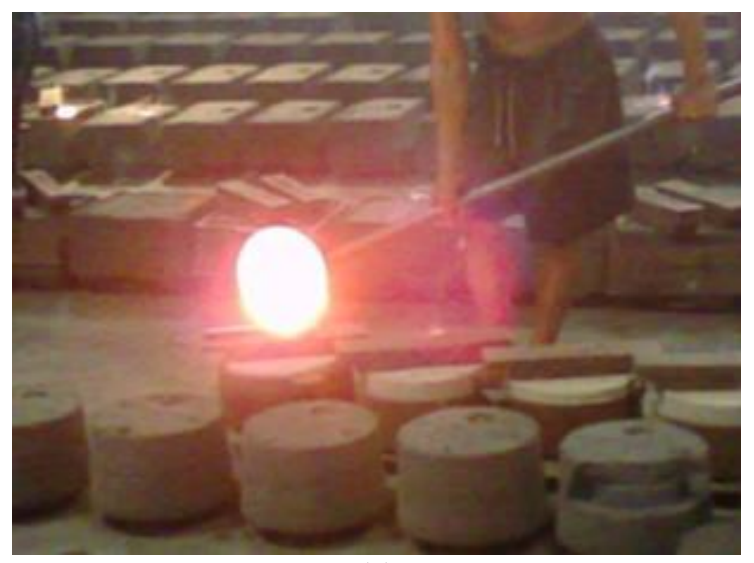

(a)

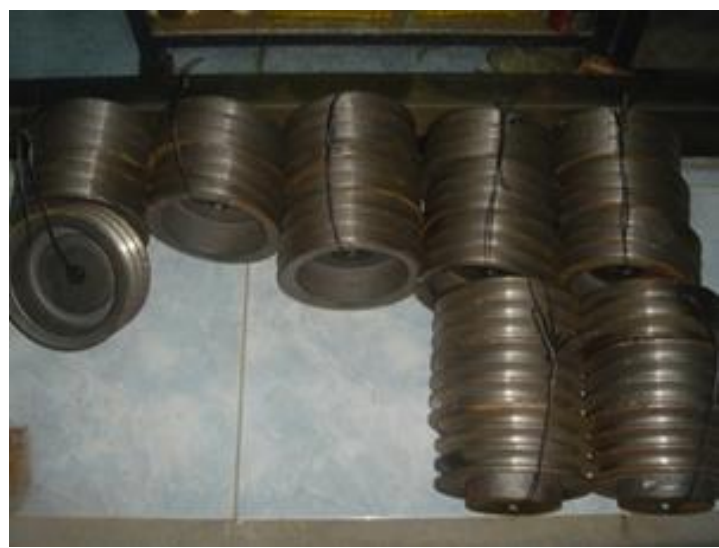

(b)

Fig. 2. (a) Pulley manufacturing by sand casting; (b) some small sand casting products.

\section{Results and discussion}

The results of compressive strength and permeability of twelve molding sand mixture experiments based on general factorial design with four levels of content and three levels particle size of rice husk are listed in Table 1.

\begin{tabular}{ccccccccc}
\hline & \multicolumn{2}{c}{ Rice husk powder } & \multicolumn{2}{c}{ Compressive strength $\left(\mathrm{kg} / \mathrm{cm}^{2}\right)$} & \multicolumn{3}{c}{ Permeability } \\
\cline { 2 - 8 } Run & Content $A($ wt.\%) & Particle size $B(\mu \mathrm{m})$ & 1 & 2 & 3 & 1 & 2 & 3 \\
\hline 1 & 1 & 106 & 0.31 & 0.30 & 0.33 & 51 & 49 & 49 \\
2 & 2 & 106 & 0.26 & 0.31 & 0.33 & 40 & 39 & 39 \\
3 & 3 & 106 & 0.22 & 0.31 & 0.31 & 32 & 33 & 31 \\
4 & 4 & 106 & 0.32 & 0.27 & 0.24 & 24 & 26 & 27 \\
5 & 1 & 212 & 0.26 & 0.28 & 0.25 & 56 & 57 & 57 \\
6 & 2 & 212 & 0.22 & 0.30 & 0.26 & 50 & 50 & 49 \\
7 & 3 & 212 & 0.14 & 0.23 & 0.20 & 55 & 50 & 51 \\
\hline
\end{tabular}




\begin{tabular}{|c|c|c|c|c|c|c|c|c|}
\hline 8 & 4 & 212 & 0.20 & 0.23 & 0.23 & 42 & 45 & 45 \\
\hline 9 & 1 & 425 & 0.25 & 0.30 & 0.31 & 65 & 67 & 70 \\
\hline 10 & 2 & 425 & 0.25 & 0.27 & 0.25 & 63 & 63 & 62 \\
\hline 11 & 3 & 425 & 0.20 & 0.23 & 0.20 & 50 & 50 & 51 \\
\hline 12 & 4 & 425 & 0.23 & 0.20 & 0.19 & 41 & 43 & 47 \\
\hline
\end{tabular}

Table 1. Experimental design and corresponding response.

The ANOVA results for compressive strength and permeability are summarized in Table 2 . The ANOVA in Table 2 shows that the model source of variability has been subdivided into three terms. The terms $A$ and $B$ represented the main effects of content and particle size of the rice husk, respectively. The term $A B$ was the interaction of the linear content factor with particle size factor of rice husk. The content and particle size of rice husk added in the mixed sand significantly affected the compressive strength whereas the interaction between the two components was not significant at the level of significance of 0.05 . On the other hand, the content and particle size of rice husk and the interaction between the two components significantly affected the permeability at the level of significance of 0.05 . The analyses of residuals from these experiments such as normal probability plot of residuals, plot of residuals versus the fitted values, and the plot of residuals in time sequence did not illustrate any major concerns about the model inadequacies and violations of underlying assumptions.

\begin{tabular}{lcccrr}
\hline Source & SS & df & MS & $F$-value & $p$-value \\
\hline Model & 0.052 & 11 & 0.0048 & 4.75 & 0.0007 \\
$A$ & 0.023 & 3 & 0.0078 & 7.79 & 0.0008 \\
$B$ & 0.025 & 2 & 0.0130 & 12.60 & 0.0002 \\
$A B$ & 0.004 & 6 & 0.0006 & 0.62 & 0.7114 \\
Pure error & 0.024 & 24 & 0.0010 & & \\
Total & 0.076 & 35 & & & \\
\hline
\end{tabular}

Table 2. ANOVA results for compressive strength.

\begin{tabular}{lrrrrr}
\hline Source & SS & df & MS & $F$-value & $p$-value \\
\hline Model & 4664.75 & 11 & 424.07 & 159.03 & $<$ \\
$A$ & 1970.53 & 3 & 656.84 & 246.32 & 0.0001 \\
& & & & & 0.0001 \\
$B$ & 2387.17 & 2 & 1193.58 & 447.59 & $<$ \\
& & & & & 0.0001 \\
$A B$ & 307.06 & 6 & 51.18 & 19.19 & $<$ \\
& & & & & 0.0001 \\
$\begin{array}{l}\text { Pure error } \\
\text { Total }\end{array}$ & 6728.00 & 24 & 2.67 & & \\
\hline
\end{tabular}

Table 3. ANOVA results for permeability.

To assist in the practical interpretation of these experiments, Figs 3 and 4 present plots of the two main effects of the content and the particle size of the rice husk on compressive strength and permeability, respectively. The main effect plots are graphs of the marginal response averages compressive strength and permeability at the levels of the content and particle size of the rice husk. Notice that the content had negative main effect; that is, decreasing the content moved the average permeability downward. On the other hand, the particle size had positive main effect; that is, increasing the particle size moved the average permeability upward. According to Fig. 5 (a), compressive strength values were not significantly different at various content levels of rice husk regardless of particle size whereas Fig. 5 (b) indicates that higher permeability was attained at low content of rice husk regardless of particle size. Permeability values for all particle sizes continuously decreased from the contents of $1 \mathrm{wt} . \%$ to $4 \mathrm{wt} . \%$. This result agreed with some previous researches. Chopra [12] studied the effect of replacing cement content with rice husk ash as supplementary cementing materials in self-compacting concrete and reported that as the content of rice husk ash increased, the permeability of the concrete decreased. Madandoust [3] stated that adding rice husk ash in Portland cement leaded to lower porosity and finer pore structures. However, particle size of $425 \mu \mathrm{m}$ gave the highest permeability. Thus, particle size of $425 \mu \mathrm{m}$ and content of $1 \mathrm{wt} . \%$ indicated the best result. 

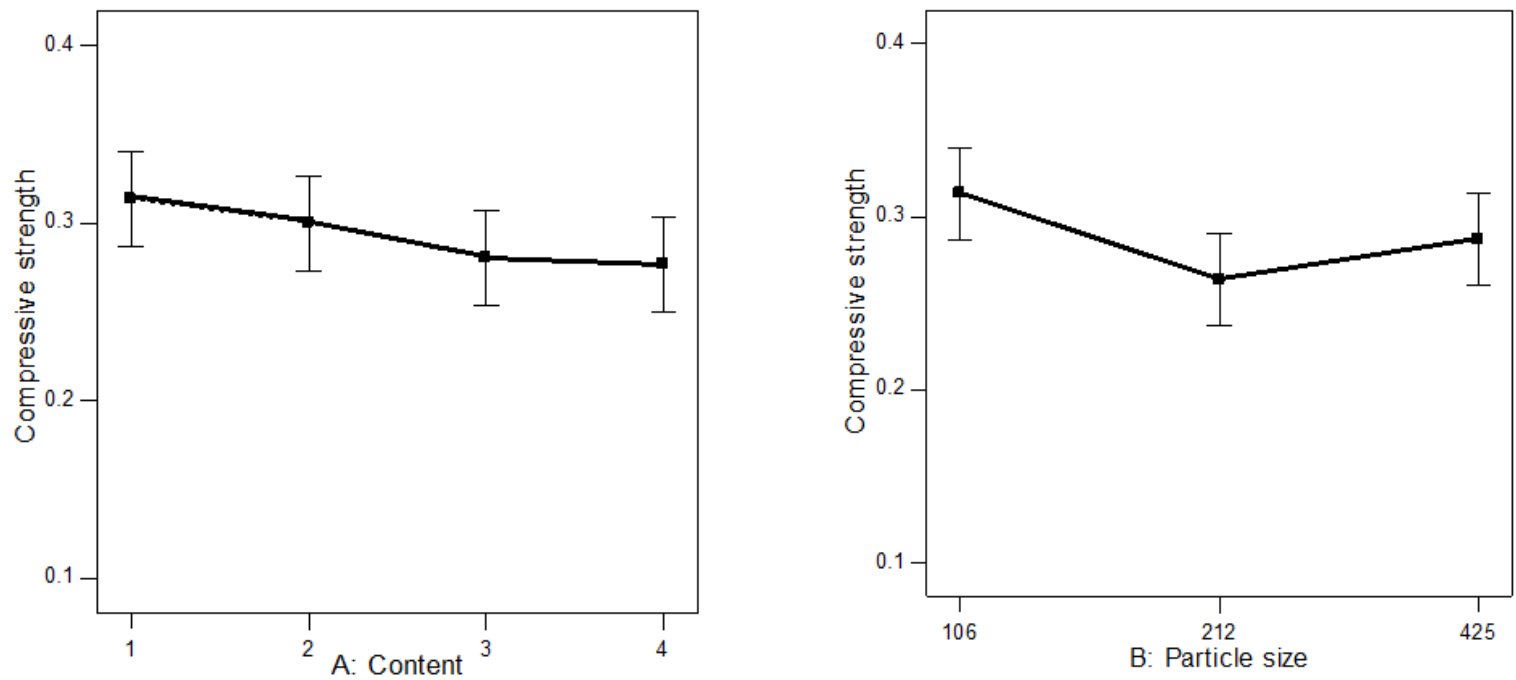

Fig. 3. (a) Main effect plot of content of the rice husk; (b) Main effect plot of particle size of the rice husk on compressive strength.
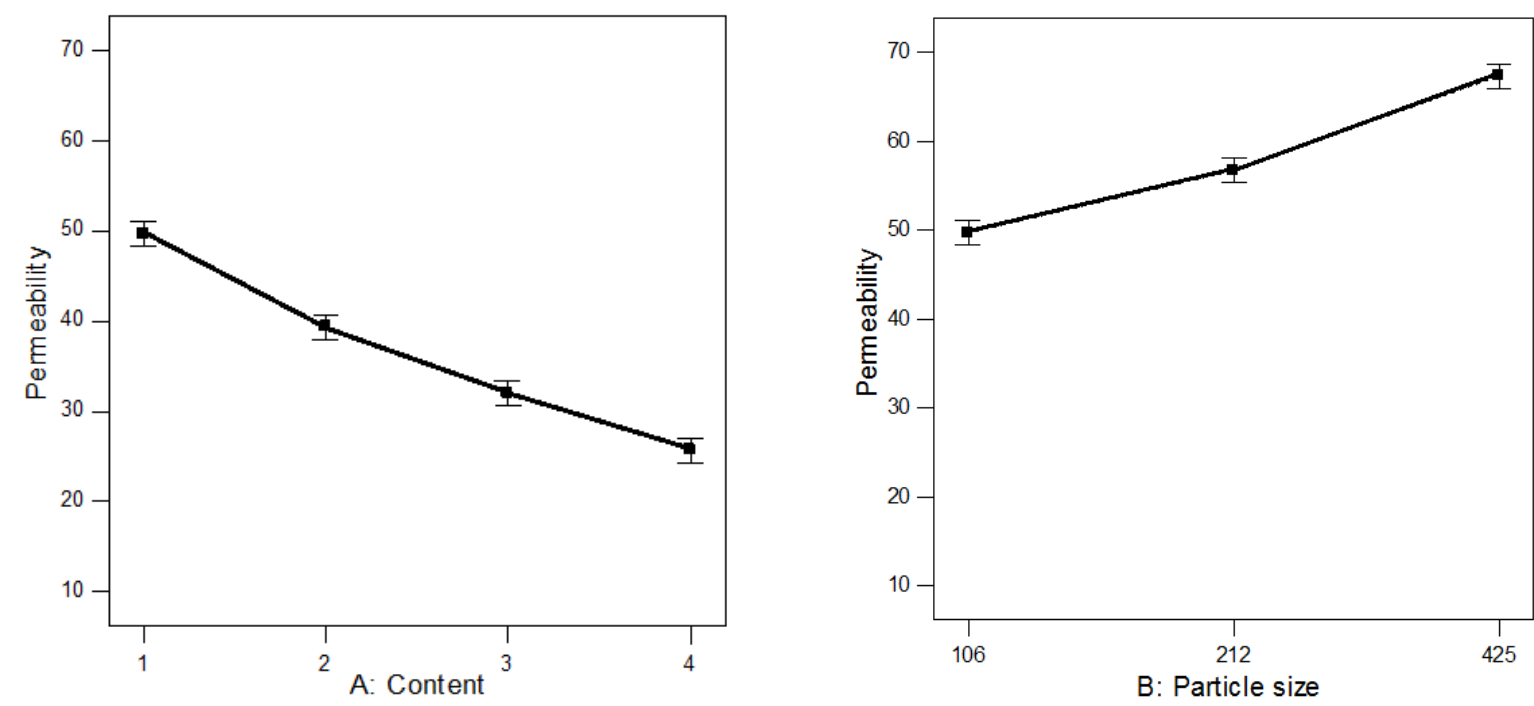

Fig. 4. (a) Main effect plot of content of the rice husk; (b) Main effect plot of particle size of the rice husk on permeability.
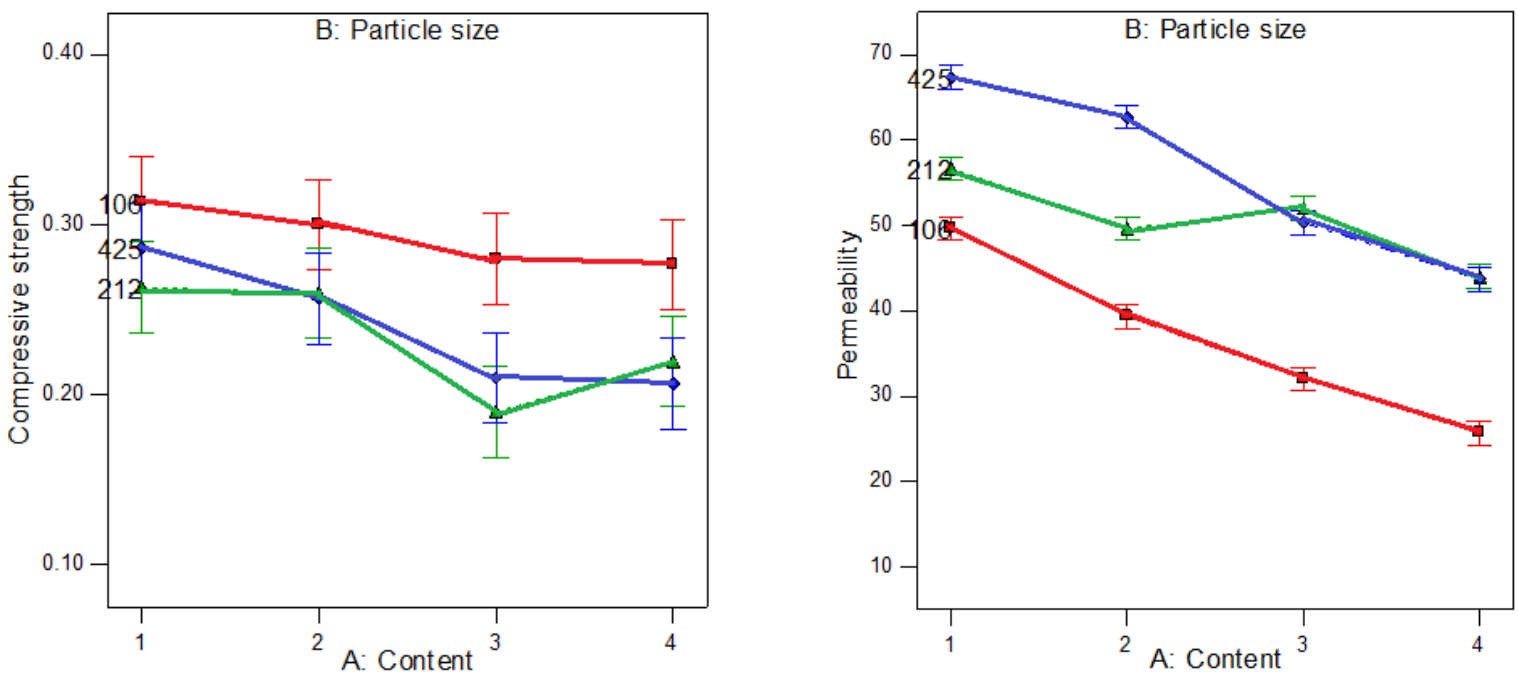

Fig. 5. (a) Interaction effect plot of content and particle size of the rice husk on compressive strength; (b) Interaction effect plot of content and particle size of the rice husk on permeability. 
The hardness values of the iron casting samples made with various mixtures of the sand molds are illustrated in Fig. 6. They were compared to hardness value of iron casting samples made with the conventional mixture of the sand mold from the factory. The results showed that averages hardness values of the iron casting samples made with various mixtures of the sand molds and with the conventional mixture of the sand mold were not significantly different.

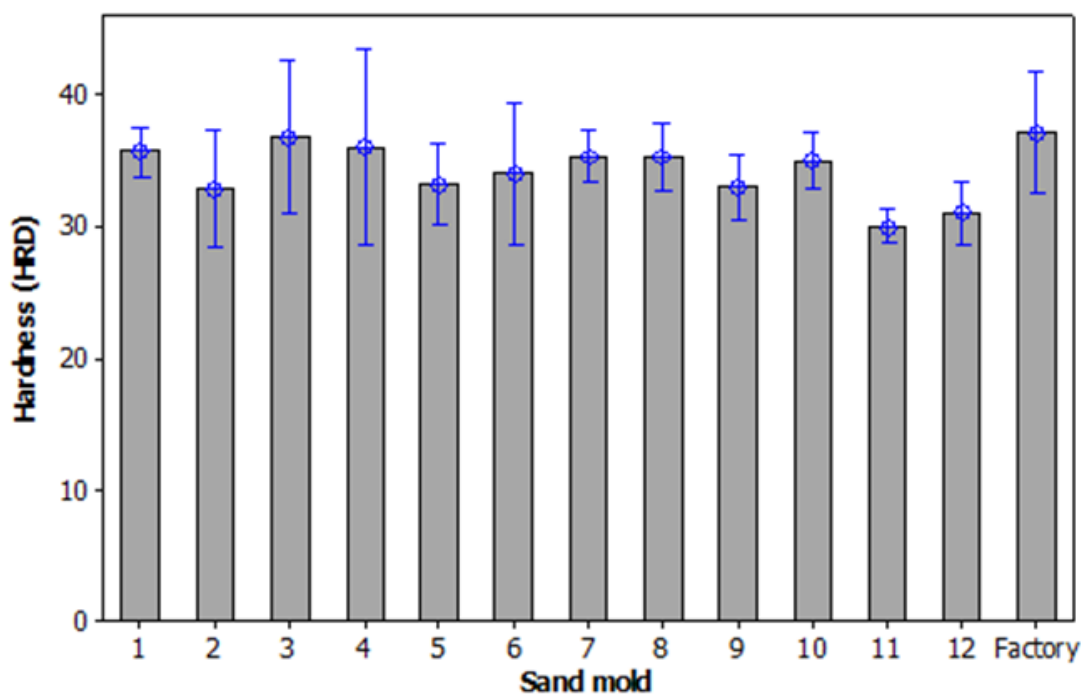

Fig. 6. Results of hardness values of the iron casting samples made with various mixtures of the sand molds.

Fig. 7 illustrates images of rough surface and microstructure appearances on the casting samples. Rough surface of the sample made with the molding sand mixture of rice husk with the particle size of $425 \mu \mathrm{m}$ and content of $1 \mathrm{wt}$.\% was better than that made with the conventional mixture of the sand mold. The foundry manufacturer can make decision how to improve the surface quality of the casting products by adding rice husk in sand mold. Mechanical properties of the casting products depend on their microstructure [10]. Two microstructure appearances on the casting samples in Fig. 7 were similar in their graphite flakes dispersion. This confirmed that hardness values of the iron casting samples made with various mixtures of the sand molds were not significantly different.

Casting product made with the particle size of $425 \mu \mathrm{m}$ and content of $1 \mathrm{wt} . \%$ mixture of the sand mold
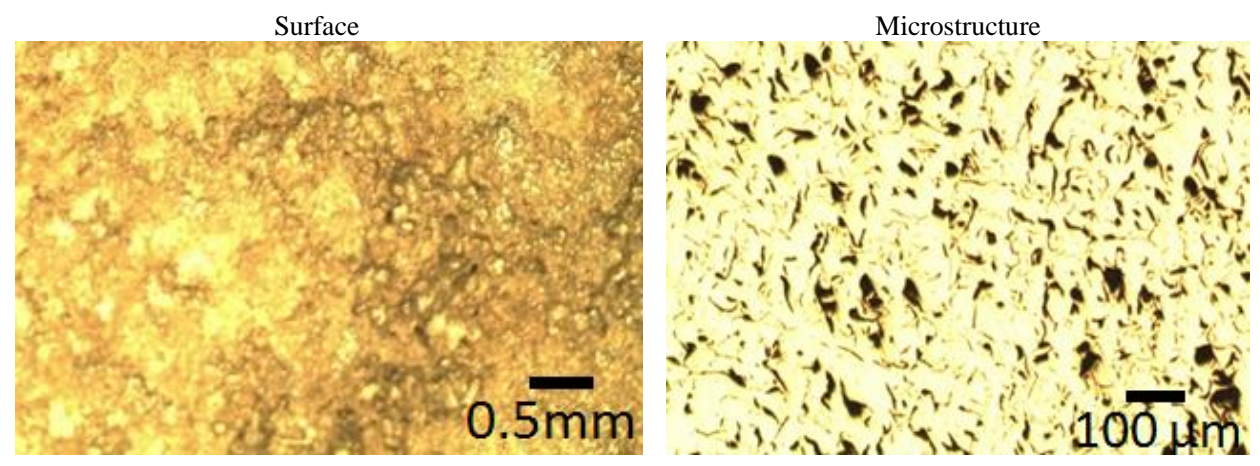

Casting product made with the conventional mixture of the sand mold
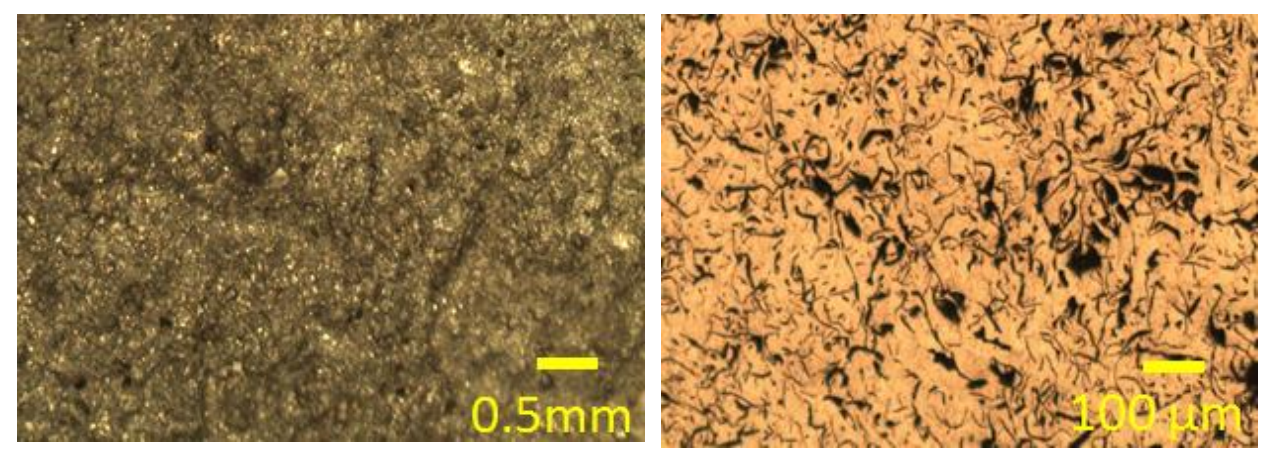

Fig. 7. Images of rough surface and microstructure appearances on the casting products made with the particle size of $425 \mu \mathrm{m}$ and content of $1 \mathrm{wt} . \%$ mixture and the conventional mixture of the sand molds. 


\section{Conclusion}

Foundry manufacturer claims that the recycled sand degrades quality of sand mold that causes product defects. The mixture components of sand mold were determined in order to improve sand mold mechanical properties and the quality of the iron casting products. The content and particle size of rice husk and recycled molding sand added to bentonite and water were investigated using general factorial design and analysis of variance and other statistical analysis techniques. The content and particle size of rice husk added in the mixed sand significantly affected the compressive strength whereas the interaction between the two components was not significant at the level of significance of 0.05 . The content and particle size of rice husk and the interaction between the two components significantly affected the permeability at the level of significance of 0.05 . Averages hardness of the iron casting samples made with various mixtures of the sand molds and with the conventional mixture of the sand mold were not significantly different. Rough surface of the sample made with the molding sand mixture of rice husk with the particle size of $425 \mu \mathrm{m}$ and content of $1 \mathrm{wt} . \%$ was better than that made with the conventional mixture of the sand mold. The research results can help the manufacturer make decisions regarding customers' satisfaction on the quality of iron sand casting products. Approaches based on different design of experiments (e.g., mixture design) are possibilities for future plan research to determine the optimal proportion of the sand mold components. Moreover, other sand mold components including modified starch [5] potato starch [6] and molasses [11] are conducted an investigation to determine the effects of sand mold mechanical properties and the quality of the iron and other metal sand casting products.

\section{Acknowledgements}

The authors would like to thank Khon Kaen University for the financial support for the conference attendance. The authors are grateful to Bowornkit Pansatien for providing SEM and the optical microscope services for investigation of rough surface and microstructure on the casting samples.

\section{References}

[1] Kundu RR, Lahiri BN. Study and statistical modelling of green sand mould properties using RSM. Inter J Mater \& Product Technol 2008;31:143-158.

[2] Van Tuan N, Ye G, Breugel K, Fraaij A, Bui D. The study of using rice husk ash to produce ultra high performance concrete. Constr Build Mater 2011;25:2030-2035.

[3] Madandoust R, Ranjbar M, Moghadam HA, Mousavi SY. Mechanical properties and durability assesment of rice husk ash concrete, Biosyetem Engr 2011;110:144-152.

[4] Rout AK, Satapathy A. Study on mechanical and tribo-performance of rice-husk filled glass-epoxy hybrid composites, Mater Des 2012;41:131-141.

[5] Zhou X, Yang J, Qu G. Study on synthesis and properties of modified starch binder for foundry. J Mater Proc Technol 2007;183:407-411.

[6] $\mathrm{Yu} \mathrm{W}, \mathrm{He} \mathrm{H}$, Cheng N, Gan B, Li X. Preparation and experiments for a novel kind of foundry core binder made from modified potato starch. Mater Des 2009;30:210-213.

[7] Saikaew C, Wiengwiset S. Optimization of molding sand composition for quality improvement of iron castings. Appl Clay Sci 2012;67-68:26-31.

[8] Paluszkiewicz C, Holtzer M, Bobrowski A. FTIR analysis of bentonite in moulding sands. J Mol Struct 2008;880:109-114.

[9] Zanetti MC, Fiore S. Foundry processes: the recovery of green moulding sands for core operations. Resources, Conservation and Recycling 2002;38:243-254.

[10] Collini L, Nicoletto G, Konecna R. Microstructure and mechanical properties of pearlitic gray cast iron. Mater Sci and Engr: A 2008;488:529-539.

[11] Xiaojian G, Yang Y, Deng H. Utilization of beet molasses as a grinding aid in blended cements. Const Build Mater 2011;25:3782-3789.

[12] Copra D, Siddique R, Kunal. Strength, permeability and microstructure ofself-compacting concrete containing rice husk ash. Biosys Engr 2015;130:72-80. 